\title{
Cistite flegmonosa severa: relato de caso
}

\section{Severe phlegmonous cystitis: case report}

\section{Resumo}

Relata-se um caso de cistite flegmonosa severa, ou cistite purulenta, decorrente de infecção por bactérias em uma fêmea da espécie canina, da raça dachshund, com nove anos de idade, apresentando disúria há aproximadamente uma semana. Exames bioquímicos foram realizados, além de análise de cálculo e exame de ultrassonografia abdominal. Os exames de bioquímica não apresentaram alterações. A análise de cálculos apresentou carbonato de cálcio/urato. A confirmação do diagnóstico foi obtida pela ultrassonografia com a visualização de uma área de aspecto heterogêneo, hipoecogênico e hiperecogênico em região caudal à bexiga. $\mathrm{O}$ animal passou por cirurgia, na qual foi retirada uma massa aderida à bexiga, e encaminhada para exame histológico, resultando em perda de revestimento epitelial e severa infiltração leucocitária. Este relato salienta a importância do diagnóstico, que pode ser realizado com o emprego de exames laboratoriais e exames de imagem, como importantes auxiliares.

\section{Abstract}

A case of severe phlegmonous cystitis or purulent cystitis due to bacterial infection is reported in a 9-year-old female dog of the Dachshund breed, presenting dysuria about a week ago. Biochemical examinations were performed, besides calculation analysis and abdominal ultrasound examination. The biochemistry exams did not present alterations. Calculation analysis showed calcium carbonate/urate. The diagnosis was confirmed by ultrasonography in which a heterogeneous, hypoechogenic and hyperechogenic aspect was seen in the caudal region of the bladder. The animal underwent surgery, in which a mass adhered to the bladder was removed and sent for histological examination, resulting in loss of epithelial lining and severe leukocyte infiltration. This report emphasizes the importance of diagnosis, which can be performed through laboratory and imaging tests as important auxiliaries. 
Bruna Higa Nakamuta ${ }^{1}$

Milton Kolber ${ }^{2}$

Nathalie Nagasse ${ }^{2}$
Rua Continental, 1106, apto. 01,

Jardim do Mar, São Bernardo do Campo/SP, Brasil

CEP: 09726-412

凶bruna.higa@gmail.com

\section{Palavras-chave}

Cão. Cistite. Diagnóstico. Infecção. Severa. Ultrassonografia.

\section{Keywords}

Cystitis. Diagnosis. Dog. Infection. Severe.

Ultrasonography. s infecções do trato urinário (ITU), ou cistites, muito frequentes em cães, apresentam menor ocorrência nos gatos (BARSANTI, 2006). Esta afecção, predominantemente de origem bacteriana, segundo estimativas, afetará um número elevado de cães em alguma fase da vida (BARSANTI, 2006; THOMPSON et al., 2011), acometendo, frequentemente, fêmeas castradas, machos castrados, fêmeas intactas e, raramente, machos intactos (BARSANTI, 2006).

A definição de ITU está relacionada à colonização microbiana do epitélio do trato urinário, como mucosa uretral, bexiga, ureteres, pelve renal, túbulos contorcidos e dutos coletores dos rins. Habitualmente, o trato urinário é um ambiente estéril, excetuando-se a uretra distal que apresenta, naturalmente, micro-organismos residentes (BARSANTI, 2006). Pode ocorrer em mais de um órgão, ou ser localizada tanto no trato inferior quanto superior (BARSANTI, 2006; SENIOR, 2011). Entretanto, quando a infecção está em um local supõe-se que o outro também esteja contaminado, pois a bexiga e a uretra proximal estão intimamente ligadas (BARSANTI, 2006). 
A ascensão de bactérias presentes na porção distal da uretra e sua multiplicação em locais de trato urogenital, usualmente desprovido de microbiota, frequentemente são de origem intestinal (JOHNSON et al., 2003). Este fenômeno ocorre devido às alterações dos mecanismos de defesa do hospedeiro, predispondo ao parasitismo (JOHNSON, 1991; JOHNSON et al., 2003).

Escherichia coli é o microrganismo mais isolado em culturas de urina de cães dentre as bactérias que causam ITU, e os relatos indicam predominância do isolamento desta bactéria em percentuais em torno de 70\% (SENIOR, 2011). O trato urinário também pode ser colonizado por fungos e leveduras. Estas infecções são raras em cães e o microrganismo mais frequentemente isolado é a Candida albicans (BALL et al., 2008; BRITO et al., 2009).

Fatores como urolitíase, neoplasias, alterações do sistema nervoso, doenças como o hiperadrenocorticismo, diabetes mellitus e corticosteróides, podem ocasionar susceptibilidade às infecções bacterianas do trato urinário inferior (CETIN et al., 2003).

O conhecimento sobre a classificação da severidade das ITUs (agudas ou crônicas) pode ajudar na formulação do tratamento e no prognóstico (LULICH; OSBORNE, 1995). Além disso, podem ser sintomáticas ou assintomáticas, sendo a assintomática, ou oculta, comum em cães, com relatos de $9 \%$ em machos intactos e de $95 \%$ em cães com hiperadrenocorticismo ou diabetes mellitus (BARSANTI, 2006; LITTMAN, 2011).

Os possíveis sinais clínicos dos cães acometidos por ITU são disúria, polaquiúria, estrangúria, hematúria e incontinência urinária, e, na maioria das vezes, não são observados sinais sistêmicos, porém quando ocorrem (febre e leucocitose), indicam que os rins também foram afetados. Entretanto, o diagnóstico não deve ser baseado exclusivamente nos sinais clínicos, pois se não for constatada a bacteriúria, não poderá ser descartada a possibilidade de infecção bacteriana, que deverá ser verificada pela urocultura (LING, 1984; BARSANTI, 2006).

A urocultura é a base laboratorial para o diagnóstico de ITU, podendo ser qualitativa (isolamento e a identificação) ou quantitativa (número de bactérias por unidade de volume, isolamento e possível identificação) (CETIN et al., 2003).

Em pacientes com suspeita de ITU, o método preferido é a cistocentese, pois fornece amostras de urina livres de contaminantes vaginais e prepuciais (LITTMAN, 2011), sendo um procedimento seguro, rápido, simples de ser realizado, além de não traumático ou doloroso, se realizado de forma apropriada (LING, 2008).

A ultrassonografia, utilizada para auxiliar o diagnóstico, propicia informações quanto à topografia, dimensão, forma, anatomia interna da bexiga e o aspecto da urina (GALLATTI; IWASAKI, 2004; BARSANTI, 2006).

\section{Descrição do caso}

Uma fêmea da espécie canina, da raça dachshund, com nove anos de idade foi atendida no Hospital Veterinário da Universidade Metodista de São Paulo, São Bernardo do Campo/SP com histórico de disúria há aproximadamente uma semana.

Foram realizados exames de bioquímica sérica, análise de cálculo e exame de ultrassonografia abdominal. Os exames de bioquímica (albumina, TGP, TGO e creatinina) não apresentaram alterações. Entretanto, na análise de cálculos, o resultado foi carbonato de cálcio/ urato. No exame de ultrassom foi visualizada uma área de aspecto heterogêneo, hipoecogênico e hiperecogênico, intimamente ligada, em região caudal da bexiga.

$\mathrm{O}$ animal foi submetido à cirurgia, encontrando-se uma massa aderida à bexiga próxima ao ureter, que foi retirada. O exame histológico efetuado revelou perda de revestimento epitelial e severa infiltração leucocitária mista e difusa de macrófagos e neutrófilos, com amplo predomínio de neutrófilos. Os urólitos de carbonato de cálcio apontados no exame de análise de cálculos também foram retirados através de sondagem.

O diagnóstico foi de cistite flegmonosa severa ou cistite purulenta, decorrente de infecção por bactérias.

\section{Discussão}

A cistite grave ou de longa duração leva frequentemente ao espessamento difuso da parede vesical, que se apresenta hiperecóica, com mucosa de superfície irregular, usualmente mais pronunciada, crânio ventralmente e, em casos graves, pode envolver toda a parede vesical (LANG, 2006). No caso relatado, o animal não apresentou parede espessada na ultrassonografia, foi observada apenas uma formação com área de aspecto hipo e hiperecogênico intimamente ligada à região caudal à bexiga, com íntima ligação.

A presença de urólitos (cálculos) ao longo do trato urinário (MAXIE; NEWMAN, 2007; OSBORNE et al., 2008) é a característica de urolitíase e podem ser formados em qualquer local do sistema urinário (OSBORNE 2008; NETA; MUNHOZ, 2008). A infecção do trato urinário inferior em cadelas, por bactérias produtoras de urease, torna o $\mathrm{pH}$ da urina mais alcalino, predispondo a formação dos cálculos (LING et al., 1998).

O exame urológico, normalmente, é suficiente para identificar tanto as doenças bacterianas, com ou sem complicações, como as demais condições neoplásicas, inflamatórias, neurológicas ou traumáticas do trato 
urinário. Entretanto, os exames de rotina adotados na prática clínica, geralmente, não são suficientes para garantir o diagnóstico.

A predisposição dos cães à ITU pode ocorrer por diversos fatores, como alterações anatômicas, doenças endócrinas, metabólicas ou neurológicas, neoplasias, dentre outras (BARSANTI, 2006; SENIOR, 2011). A predisposição em relação ao sexo ainda é controvérsia, Osborne e Stevens (1999) e Seguin et al. (2003) afirmam que fêmeas caninas são acometidas por cistite bacteriana com maior frequência do que os machos, atribuindo-se como causa provável a proximidade entre a vulva e o ânus, e a uretra curta. Entretanto, Ferian et al. (2007) e Pappaíardo et al. (2007) relatam diversos casos clínicos com a predominância do acometimento dos machos em relação às fêmeas.

Quanto ao fator idade e raça, ainda não existe um consenso, sendo muito variável e sem associação predisponente (OSBORNE; STEVENS, 1999; NORRIS et al., 2000; CETIN et al., 2003; PAPPAÍARDO et al., 2007). Assim, diversos fatores descritos podem predispor os cães à ITU, como alterações anatômicas, doenças endócrinas, metabólicas ou neurológicas, neoplasias, dentre outras (CETIN et al., 2003; BARSANTI, 2006; SENIOR, 2011).

Os exames complementares para o diagnóstico das doenças vesicais devem incluir diagnóstico por imagem de acordo com as necessidades e conveniências (CARVALHO, 2008). A ultrassonografia auxilia no diagnóstico das infecções do trato urinário (GALLATTI; IWASAKI, 2004; LANG, 2006), e no caso relatado foi essencial para o diagnóstico e tratamento, não descartando-se também o exame histopatológico, que possibilita a diferenciação entre neoplasias e pólipos, que possuem tratamento e prognósticos diferenciados.

\section{Conclusões}

Os exames complementares aplicados ao diagnóstico das ITUs devem empregar o diagnóstico por imagem como recurso auxiliar que, neste caso, foi essencial para o diagnóstico e tratamento do animal. Entretanto, não deve ser descartado o exame histopatológico, que também fornece subsídios para o prognóstico diferenciado e tratamento adequado. (-)

\section{Referências}

BALL, K. R. et al. Antimicrobial resistance and prevalence of canine uropathogens at the Western College of Veterinary Medicine Veterinary Teaching Hospital. Canadian Veterinary Journal, Ottawa, v. 49, p. 985-990, 2008.
BARSANTI, J. A. Genitourinary infections. In: GREENE, C. E. Infectious diseases of the dog and cat. 3. ed. St Louis: Saunders/Elsevier, 2006. p. 935-961.

BRITO, E. H. S. et al. Candidose na Medicina Veterinária: um enfoque micológico, clínico e terapêutico. Ciência Rural, Santa Maria, v. 39, n. 9, p. 2655-2664, 2009.

CARVALHO, M. B. Semiologia do sistema urinário. In: FEITOSA, F. L. F. Semiologia Veterinária: a arte do diagnóstico. 2. ed. São Paulo: Roca, 2008. p.389-409.

CETIN, C. et al. Bacteriological examination of urine samples from dogs with syntons of urinary tract infection. Turkish Journal of Veterinary and Animal Sciences, Ankara, v. 27 , p. $1225-1229,2003$.

FERIAN, P. E. et al. Estudo clínico, laboratorial e microbiológica de infecções urinárias em cães: 14 casos. Acta Scientiae Veterinariae, Porto Alegre, v. 35, n. 2, p. 581-582, 2007.

GALLATTI, L. B.; IWASAKI, M. Estudo comparativo entre as técnicas de ultrassonografia e cistografia positiva para detecção de alterações vesicais em cães. Brazilian Journal of Veterinary Research and Animal Science, São Paulo, v. 41, n. 1, p. 3-11, 2004.

JOHNSON, J. R. Virulence factors in Escherichia coli urinary tract infections. Clinical Microbiology Reviews, Washington, v. 4, p.80-128, 1991.

JOHNSON, J. R. et al. Identification of urovirulence traits in Escherichia coli by comparison of urinary and rectal $E$. coli isolates from dogs with urinary tract infection. Journal of Clinical Microbiology, Washington, v. 41, p. 337-345, 2003.

LANG, J. Urinary tract. In: MANNION, P. Diagnostic ultrasound in small animal practice. Oxford: Blackwell, 2006. p. 109-144.

LING, G. V. Therapeutic strategies involving antimicrobial treatment of canine urinary tract. Journal of the American Veterinary Medical Association, Toronto, v. 185, n. 10, p. 1162-1164, 1984.

LING, G. V. Infecções bacterianas do trato urinário. In: ETTINGER, S. J.; FELDMAN, E. C. Tratado de medicina interna veterinária. 5. ed. São Paulo: Manole, 2008. v. 2. p. 1768-1776.

LING, G. V. et al. Renal calculi in dogs and cats: prevalence, mineral type, breed, age, and gender interrelationships (19811993). Journal of Veterinary Internal Medicine, Philadelphia, v. 12, p. $11-21,1998$

LITTMAN, M. P. Diagnosis of infectious diseases of the urinary tract. In: BARTGES, J.; POLZIN, D. J. Nephrology and urology of small animals. Ames: Wiley-Blackwell, 2011. p. 241-252.

LULICH, J. P.; OSBORNE, C. A. Bacterial infections of the urinary tract. In: ETTINGER, S. J.; FELDMAN, E. C. Textbook of veterinary internal medicine. 4. ed. Philadelphia: Saunders, 1995. p. 1775-1788. v. 2. 
MAXIE, M. G.; NEWMAN, S. J. The urinary system. In: MAXIE, M. G. (ed.). Jubb, Kennedy, and Palmer's pathology of domestic animals. 5. ed. Philadelphia: Saunders Elsevier, 2007. p. 425-522. v. 2.

NETA, E. S. M.; MUNHOZ, A. D. Urolitíase em cães e gatos: uma revisão. Medvep, Curitiba, v. 6, n. 17, p. 24-34, 2008.

NORRIS, C. R. et al. Recurrent and persistent urinary tract infections in dogs: 383 cases (1969 1995). Journal of the American Animal Hospital Association, Lakewood, v. 36, p. 484-492, 2000.

OSBORNE, C. A.; STEVENS, J. B. Urinalysis: a clinical guide to compassionate patient care. Shawnee Mission: Bayer Corporation, 1999. 214 p.

OSBORNE, C. A. et al. Analysis of 451,891 canine uroliths, feline uroliths, and feline urethral plugs from 1981 to 2007: perspectives from the Minnesota Urolith Center. Veterinary Clinics of North America: small animal practice, Philadelphia, v. 39, p. $183-197,2008$.

PAPPAÍARDO, M. C. F. et al. Estudo retrospectivo de 193 uroculturas e antibiogramas em cães e gatos. Acta Scientiae Veterinariae, Porto Alegre, v. 35, n. 2, p. 596-598, 2007.

SEGUIN, M. A. et al. Persistent urinary tract infections and reinfections in 100 dogs (1989-1999). Journal of Veterinary Internal Medicine, Philadelphia, v. 17, p. 622-631, 2003.

SENIOR, D. Urinary tract infection: bacterial. In: BARTGES, J.; POLZIN, D. J. Nephrology and urology of small animals. Ames: Wiley-Blackwell, 2011. p.710-716.

THOMPSON, M. F. et al. Canine bacterial urinary tract infection: new developments in old pathogens. The Veterinary Journal, London, v. 190, p. 22- 27, 2011. 